\title{
The milk and the honey: ethics of artificial nutrition and hydration of the elderly on the other side of Europe
}

Tina Garanis-Papadatos and Aristotle Katsas National School of Public Health and "Evangelismos" Hospital, Athens, respectively

\begin{abstract}
Many health problems that elderly people face today relate not only to the nature of their affliction but also to the kind of treatment required. Such treatment often includes artificial nutrition and hydration, (ANH) a procedure which, despite its technical and invasive character, is still considered to be vested with symbolic meanings. It is precisely during the efforts to reach a legal consensus that the discrepancies between various cultural contexts become obvious. The following case explores the Greek clinical territory in comparison with the international situation, and the reasons why, in Greece, the right to refuse treatment is not necessarily interpreted as including the right to refuse artificial nutrition and hydration as well.
\end{abstract}

(Fournal of Medical Ethics 1999;25:447-450)

Keywords: Artificial nutrition and hydration; autonomy; human rights; persistent vegetative state

\section{Introduction}

Problems of the elderly population today derive not only from the nature of their illness or disease but also from the kind of treatment or intervention required. Modern technology has transformed the face of these interventions and has added numerous dimensions to the meaning of the word "choice". Thus, elderly people have been especially affected by these changes, as paternalistic decision making is considered justified in their case because of their presumed incompetence independently to manage their lives. ${ }^{1}$ Artificial nutrition and hydration (ANH) constitutes an example of such modern interventions which can prolong considerably the life of the patient without, however, restoring her health. The "unreasonable" character of promoting only one function of the human organism was commented upon by Galen centuries ago: “.. nature alone has the power to expand a body in all directions so that it remains unruptured and preserves completely its previous forms" (emphasis added). The following case illustrates some of the main problems deriving from such a peculiar situation.

\section{Case analysis}

A lady aged 82, incapacitated for over two years because of arthritic problems and almost blind after unsuccessful treatment of cataracts and glaucoma, suffered a severe cerebral vascular accident resulting in semi-coma. Artificial nutrition and hydration were immediately given to her through a nasogastric tube. During the first six weeks of hospitalisation, although nobody had let the patient know the severity of her condition, she repeatedly expressed her wish to die by making signs, by uttering with difficulty a few words and by trying to remove the feeding tube. Her children, aware of their mother's life-long aversion to hospitals and medicines, talked with the physician about the possibility of withdrawing treatment. The physician made clear to the family that he would not honour such a request, mentioning also the lady's past medical history of mild depression. Nevertheless, one week later, after her condition had deteriorated to full and irreversible coma, he agreed to withdraw nutrition and maintain only IV fluids. The old lady survived for another two weeks without respiratory or other complications and died rather suddenly from a second vascular accident. After her death, her son said bitterly to the doctor, that had he agreed to their request to withdraw all kinds of treatment, his mother would have died sooner and probably suffered less. The doctor calmly replied that simple hydration was not "any kind of treatment" but the most fundamental form of care that he, as a physician, felt obliged to provide to any patient, and that although he was not in favour of unnecessarily prolonging a dying patient's life, letting a patient die from dehydration was not his idea of a dignified and peaceful death. To do so, he concluded, would go against all medical and religious traditions in Greece and would be contrary to his personal beliefs.

\section{The Greek legal framework}

One of the most important issues raised in this case concerns the place of autonomy in the Greek 
legal system as well as in the Greek hospital context, since most deaths in Greece occur today in the hospital environment. ${ }^{3}$

The Greek constitution of 1975 provides the most important directions regarding respect for human beings and self-determination. Section 2 para 1 stipulates that respect and protection of the value of a human being constitute the primary obligation of the state. Section 5 para 1 stipulates a person's right to develop freely his or her personality, insofar as this does not infringe upon the rights of others or violate the constitution or public morality. Section 21 para 3 refers to the state's obligation to care for the health of the citizens and to adopt all special measures necessary for the protection of youth, old age, disability and for the relief of the needy.

Recent legislation has for the first time directly acknowledged the rights of patients, which, until this legislation was introduced, had been only indirectly protected by civil, penal and constitutional law. ${ }^{4}$ These rights, about which patients are still not well informed, include, among others, the right to consent to or refuse any diagnostic or therapeutic act. In the case of an incompetent patient, this right is exercised by the patient's legal guardian. However, the enactment of a law which establishes patients' rights does not automatically entail the establishment of a "right to die" or that Greek society, and especially the Greek medical profession, are prepared to accept and endorse such a right. Moreover, lack of public debate and the lack of guidelines from Greek medical associations does not help to clarify the extent of the legislator's intentions or to interpret the right to refuse treatment as the simultaneous establishment of an equal right to refuse artificial nutrition and hydration. Thus, "when in doubt", traditional views favouring preservation of life, still prevail.

An issue which is raised in this case and is also relevant to the exercising of autonomy in the clinical setting, concerns the notion of psychiatric depression. It has been argued that mild depression does not entail absence of competency. ${ }^{5}$ Related to this is the question of whether psychiatrists should be involved in medical decisions at the end of life and if so what their exact role should be. ${ }^{6}$ The usual practice in Greece does not involve psychiatrists in the final decision making, the reasons for this being the association with the "stigma" of severe mental disorders, the in-family support mechanisms and the simple shortage of psychiatrists in state hospitals.

\section{The milk and the honey}

The distinction - and the confusion - between the nature of ANH as medical treatment or as the simplest form of care that must be provided to $\underset{\mathbb{Q}}{\stackrel{2}{\infty}}$ human being in suffering, is controversial as the two notions, once used in a parallel an f $_{\text {. }}$ complementary sense have now become the two opposite ends of the spectrum.

In The Bible (Exodus III.8) God announces to Moses the promised land of Canaan, describing as "... a land flowing with milk and honey", is other words as a land bearing everything neces。 sary for the preservation of life. ${ }^{7}$ Obviously, th importance of food goes far beyond that of nutrition and is full of symbolic meanings, the main. ones among them being the expression of love anฮ caring. "Food and the way in which it is being consumed is one of the ways a human being com municates with her environment in order to ensure the harmony of body and soul". ${ }^{8}$ Accordo ing to Helman: "in every human society food is way of creating and expressing the relationships between people". ${ }^{9}$ Lack of food, therefore, or dis? continuation of its provision severs all links and ends all relationships with one's environment Food intake is the main prerequisite of life. human being who is starving can think of nothing other than food, as nothing else really matters. Food represents the main link of a human beingt the world of the living and a person who refutes food makes it clear that she does not want to be part of this world any longer. Refusal of food क्षn water is the most certain way to the end, it is ". biologically final ...”. ${ }^{10}$ The desire to die as such sometimes said to prove incapacity but this viem has been rejected. "The choice of this particula way to die is not unusual: it has been observed that even in early stages of dementia, patients show refusal of feeding. ${ }^{12}$ Lynn and Childress argue that a similar treatment may be forgone when it futile, when there is no benefit or when the burdef outweighs the benefit. ${ }^{13}$ Childress and Dalle Mura reject the symbolical meaning of $\mathrm{ANH}$ and the view that not using it is equal to murder. However, current debate in the United States regarding forgoing of $\mathrm{ANH}$ for paediatric patients reveals the obvious reluctance of physicians to discontinue artificial nutrition whereas the same physicians are willing to withdraw other forms of life-sustaining treatment. ${ }^{15}$

In the Greek hospital environment nutritioł and hydration are considered to be a form of caro and in particular the latter is almost never withheld from a dying patient.

Thus, the approach of this particular physician does not deviate from the norm of the majority of his peers, who follow a deontological trend base $\frac{P}{D}$ on a deeply embraced Hippocratic tradition From the legal point of view an omission to ac

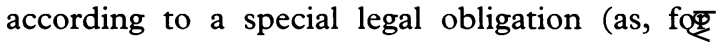


instance, the one undertaken by the doctor towards her patient) constitutes a criminal offence.Thus, the failure to provide nutrition and hydration to an incompetent patient, construed in a narrow legal sense, may be punished by law. It may be worth mentioning here the Declaration of Tokyo, according to which "where a prisoner refuses nourishment and is considered by the doctor as capable of forming an unimpaired and rational judgement concerning the consequences of such a voluntary refusal of nourishment, he or she shall not be fed artificially..." ${ }^{16}$ Greek authorities would indeed follow this declaration and refrain from imposing nourishment on a prisoner who is on hunger-strike. ${ }^{17}$ Thus, curiously enough, persons in prison are offered the possibility of a choice often denied to free and competent citizens.

In Greece cases regarding withdrawal of ANH from patients have never reached the courts. According to a recent survey of Greek doctors' attitudes towards the management of patients in persistent vegetative state (PVS), only $14 \%$ of the respondents had been involved in considering a decision to withdraw artificial nutrition and hydration, a percentage considerably lower than the respective one in other European countries, with the exception of France ${ }^{18}$; interestingly enough, these two countries were the only ones, among those surveyed, representing the south of Europe.

It should be briefly pointed out that, although financial ramifications of ANH are not mentioned in this case, they are manifold and raise questions of justice and resource allocation. An economic analysis would lie outside the scope of this paper, nevertheless one cannot ignore two crucial factors: cost and benefit. This discussion is closely related to the real goals of medicine today and especially to “... medicine's capacity to keep desperately sick bodies going even when health has been irrevocably lost". ${ }^{19}$ So, what is ANH really aiming at, restoring health or supporting the biological existence of an organism which has irreversibly lost consciousness and awareness? It is certainly achieving the latter, nevertheless it has been claimed that medicine should also aspire to "respect human choice and dignity". ${ }^{20}$ In the case presented here, which is not an exceptional one, it is clearly shown that the wishes of the patient were overridden; they simply did not constitute a decisive factor in the forming of the physician's opinion about the "futility" of ANH. At this point, an approach based on narrative ethics could provide a useful perspective. This approach takes into consideration the patient's life-history, a method well known by social anthropologists since the 19th century. ${ }^{21}$ According to narrative ethics the care giver must focus not only on ethical principles but also on the various aspects of the life of the patient concerned, on his choices, emotions, beliefs and ideas. In this way, medical decisions are not taken in a benevolent paternalistic vacuum but become a part of a continuum in a patient's story, respectful of the patient's previous choices.

\section{The international legal framework}

The most extended bibliography regarding ANH issues and the most famous legal cases come from the United States where legal consensus regarding withdrawal of treatment has been reached as a result of a series of famous cases, the most well known among them being: Barber in 1983; Bouvia in 1984; Brophy and Conroy in 1986, and Cruzan in $1990 .{ }^{22-28}$ According to this consensus, ANH constitutes medical treatment and not care, a fact which allows ANH to be stopped when it is decided that treatment must cease.

In Europe the situation is not very clear. A few years ago it was pointed out that the British as well as the other European courts would gradually have to move in the direction of the Convention on Human Rights and Biomedicine, which would bring closer the American and the European way of dealing with such issues. ${ }^{29}$ Despite the casecentred approach of the House of Lords in the case of A Bland, the drafting of the Convention on Human Rights and Biomedicine in 1997 has shown the correctness of this view. ${ }^{30}$ A similar approach may prove to be an important element of the Greek situation.

\section{Epilogue and conclusion}

Although efforts are being made to reinforce patients' autonomy in the Greek clinical context, when delicate and unusual matters such as withdrawal of artificial nutrition and hydration are concerned, traditional approaches prevail. This sort of paternalism makes it quite unlikely that at present a request for termination of $\mathrm{ANH}$ would be honoured in Greece. As, however, physicians increasingly recognise that they must be able to justify their actions by using solid arguments and not just by invoking the inherent value of well and long-established patterns of practice, an approach based on human rights and patients' rights in particular, will probably play a decisive role in the future. Narrative ethics should also gain ground. The issue of ANH, however, will remain a thorny one as it reflects the conflict between two choices which may be equally tragic. Greeks are a people who, despite their deep religious beliefs, do not 
hesitate to make their own choices. Individual attitudes, however, favouring one's own death as a result of a certain choice, come into conflict with the austerity and the rigidity of the law. It is the perennial conflict between the Christian ethos, according to which all life is sacred, and the independence of Mediterannean undisciplined liveliness; the very conflict between what is human and merciful and what is righteous; a conflict which the Greeks have managed to transform into a co-existence and co-habitation of beliefs and into a way of life which has a strange ability to match together contradictory values. This contradiction has been exquisitely reflected in the verses of the great Greek poet C Cavafy ${ }^{31}$ :

“...upright and just in all their actions, yet filled with pity and compassion ...

... telling the truth always, and yet holding no hatred against liars ..."

\section{Authors' note}

This paper is a modified version of a paper included in the EC BIOMED project under the title, Collaborative development of European medical ethics practitioners' education.

Dr Tina Garanis-Papadatos, PhD, MA in Medical Law and Ethics, is a Lawyer and a Research and Teaching Fellow in the Department of Public Health, National School of Public Health, Athens, Greece. Aristotle Katsas MD, FACS, is Director of Surgery at the "Evangelismos" Hospital, Athens, Greece.

\section{References}

1 Muir Gray JA. The health care of the elderly. In: Gillon R, Lloyd A, eds. Principles of health care ethics. Chichester: John Wiley, 1994:711-20.

2 Galen. On the natural faculties. In: King LS, ed. History of medicine. Suffolk: Penguin, 1971.

3 Plati ChD. Coping with death at home, in a general hospital, in a hospice. Nosokomiaka Chronica 1986;48:333-8.

4 Law 2071/92 for the Modernization and organization of the National Health Service. Philo Ephimeridos Kiverniseos A' (government journal) 123/15.7.1992, section 47. Law 2519/97, Philo Ephimeridos Kiverniseos A'165/21.8.1997.

5 Sullivan MD, Youngner SJ. Depression, competence and the right to refuse life-saving medical treatment. American fournal of Psychiatry 1994;151:971-8.
6 Anonymous [editorial]. Psychiatry's undiscovered countr American fournal of Psychiatry 1994;151:953-5.

7 The Bible. Exodus III.8.

8 Imellos SD. Issues of traditional material life. Athens: Society f the promulgation of Useful Books, 1993 (in Greek).

9 Helman C. Culture, health and illness. Bristol: Wright, 1986.

10 Derr PG. Why food and fluids can never be denied. Hastin Center Report 1986;16,2:28-30.

11 Powell T, Lowenstein B. Refusing life-sustaining treatme after catastrophic injury: ethical implications. Fournal of $\mathrm{La}$ Medicine and Ethics 1996;24:54-61.

12 Norberg A. Ethics in the care of the elderly with dementia. In Gillon R, Lloyd A, eds. Principles of health care ethif Chichester: John Wiley, 1994:721-31.

13 Lynn J, Childress JF. Must patients always be given food a water? Life choices. Washington DC: Georgetown Universit Press, 1995.

14 Childress JF, Dalle Mura SL. Caring for patients and caring for symbols: reflections on artificial nutrition and hydration Biolaw 1984;1:s4.

15 Nelson LJ, Hylton Rushton C, Cranford RE, Nelson RM Glover JJ, Truog RD. Forgoing medically provided nutrition and hydration in pediatric patients. Fournal of Law, Medicine ande Ethics 1995;23:33-46.

16 World Medical Association. Declaration of Tokyo. Statement \& torture and other cruel, inhuman or degrading treatment or punis ment. Tokyo: World Medical Association 1975

17 Anapliotou-Vazeou I. General principles of medical law. Athen Sakkoulas Editions, 1993.

18 Garanis T, Stranjalis G. A report of a survey of Greek doctors' attitudes on the management of patients in persistent vegetative state Athens: Department of Public and Administrative Healt National School of Public Health, 1998.

19 Daniels N. Justice, fair procedures and the goals of medicin Hastings Center Report 1996;26,6:10-12.

20 The goals of medicine. Setting new priorities. Report of international project of the Hastings Center Report. 1996;26,6 special supplement

21 Bertaux D. Introduction. In: Bertaux D, ed. Biographyo society: the life-history approach in the social sciences. London erly Hills: International Sociological Association/Sage, 19\&:

22 Barber v Superior Court, 195 Cal Rptr 484 (Cal App 2d Dis 1983).

23 Bouvia v Superior Court, 225 Cal Rptr 297 ( Cal App 2d Dis 1986).

24 Brophy PE v New England Sinai Hospital, Inc 497 NE 2d 6 亘 Mass 1986.

25 Claire Conroy 468 A 2d 1209 (1986), New Jersey Supren⿸户 Court.

26 Cruzan v Director, Missouri Dept of Health, 110 S Ct 284 2852 (1990).

27 American Academy of Neurology. Position statement. Certa aspects of the care and management of profoundly and irreversibly paralyzed patients with retained consciousness an cognition. Neurology 1993;43:222-3

28 Bernat JL, Cranford RE, Kittredge FI, Rosenberg Ri Competent patients with advanced states of permanent parale sis have the right to forgo life-sustaining therapy. Neurolos 1993;43:224-5.

29 Kennedy I. Health law and ethics: an agenda for the 90s. Bulle tin of Medical Ethics 1991;70:16-21.

30 Airedale National Health Service Trust v Bland [1993] 1 A ER 821.

31 Cavafy C.Thermopylae. In: Friar K, ed. Modern Greek Poet Athens: Efstathiadis Group SA, 1997.

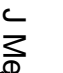

